\title{
VENA KAVA SUPERIOR SENDROMU VE CERRAHISI
}

\author{
Bedrettin YILDIZELi \\ Marmara Üniversitesi Tıp Fakültesi, Göğüs Cerrahisi Anabilim Dalı, İstanbul, Türkiye \\ e-posta: byildizeli@marmara.edu.tr \\ doi:10.5152/tcb.2011.24
}

\section{VENA KAVA SUPERIOR SENDROMU}

Vena Kava Superior Sendromu (VKSS) sıklıkla, lenfoma ve akciğer kanseri gibi malignansilerin bir komplikasyonudur. VKSS sıklığı alta yatan malignansiye göre değişmekle beraber, akciğer kanseri hastalarının \%2-4'ünde VKSS gelişebilir $(1,2)$. Küçük hücreli akciğer kanserinde bu oran \%10'lara ulaşır.

Vena Kava Superior Sendromu ilk olarak 1757'de William Hunter (1) tarafından sifilitik aortik anevrizmalı bir olguda tanımlanmıştır. Amerika Birleşik Devletlerinde yılda yaklaşık 15,000 vaka bildirilmektedir. Yetişkinlerin \%95'inde neden primer intratorasik yada metastatik tümördür. Diğer yandan, santral venöz kateter ve 'pace maker' kullanımının artması ile benign etyolojiye bağlı VKSS olguları artmıştır. Çocuklarda, T-hücreli lösemi ve lenfoma VKKS'un en sık nedenlerdir.

Bu yazıda vena kava superior sendromu kliniği ve tedavisi ile vena kava superior invazyonu yapan malign veya benign hastalıkların cerrahi tedavileri sunulmuştur.

\section{Anatomi}

Vena kava superior sendromu baş, üst ekstremite, toraks ve sağ atrium'dan normal venöz dönüş kesildiğinde oluşur. Sağ ve sol brakiosefalik venler, sağ atrium ve azygos'tan oluşan Vena kava superior (VKS), düşük basınçlı üst mediastende kısıtı bir alana yerleşmiş bir yapıdır. Herhangi bir dış bası, tümör, lenf bezi, anevrizma veya tromboza neden olan intravenöz kateterler nedeniyle VKS tıkanabilir.

Vena kava superior'un dört kollateral yolu bulunmaktadır (1):
1. Azygoz ven sistemi; sağ ana pulmoner arter ve ana bronş üzerinden direk olarak VKS'a açılır

2. İternal torasik venöz sistem; superior ve inferior epigastrik venler ve eksternal ve common iliak venlerden gelen sirkülasyon, internal torasik venlerden, vena kava inferiora açılır.

3. Vertebral venöz sistem; "sinüz venöz" ve bilateral brakiosefalik venler interkostal, lumbar ve sakral venlerden kanı alır ve vena kava inferiora dökülür

4. Eksternal torasik venöz sistem; süperfisyal kollateral sistem ile subklavian ve aksiller venden gelen kan lateral torasik vene ulaşır, torakoepigastrik ve superfisyel venler ile femoral vene dökülür.

\section{Etyoloji (Tablo 1)}

Vena kava superior sendromu aşağıdaki sebeplere bağlı gelişir:

1. Kompresyon; malign veya benign lezyonlar

2. İnvazyon; malign tümörler

3. Tromboz; hiperkoagulabilite (malignansi ve polisistemi), intimal hasar (venöz yollar) ve staz (dıştan bası)

4. Konstriksiyon; mediastinal fibrozis

$\mathrm{Bu}$ mekanizmalar sonucu, vena kava'daki venöz

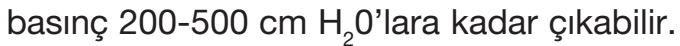

Vena Kava Superior Sendromu sonucu internal mamarian, azygos, hemiazygos, lateral torasik, torakoepigastrik ve vertebral venlerde kollateral sirkülasyon gelişir. Akut vena kava superior tıkanıklıklarında, kollateral sirkülasyon gelişmediğinden bu belirgin klinik soruna yol açar. Kronik obstrüksiyonlarda ise, bu kollateral sirkülasyon oluştuğundan VKSS'ı klinik belirti vermeyebilir. Azygos venin üzerindeki tıkanıklıklarda VKSS'u nadir semptom verirken, azygos venin altında- 
Tablo 1. Vena kava superior sendromunda etiyoloji

Malignansi (\%95)

Akciğer kanseri (\%80)

Küçük hücreli kanser

Küçük hücreli dışı akciğer kanseri

Lenfoma (en sık non-Hodgkin lenfoma)

Timoma

Mediastinal germ hücreli tümörler

Mediastinal metastazlı solid tümörler (en sık meme kanseri)

Diğerleri (\%5)

latrojenik: Pacemaker ve defibrilatör telleri, santral venöz kateterleri, post-radyasyon vasküler fibrozisi

Enfeksiyöz hastalık: Mediastinal fibroz (tüberküloz, sifiliz, histoplasmosis, aktinomikoz, aspergilloz, blastomikoz, filariasis, nocardiosis'in direkt yayılımı)

Diğer: Fibröz mediastinit, sarkoidoz, sklerozan kolanjit, planjon guatr, aortik anevrizma, fibröz mezotelioma, Behçet hastalığı, Vena kava superior ektazisi

Hughes-Stovin sendrom: multipl pulmoner arter anevrizması ve derin ven trombozu

ki tıkanıklarda vena kava inferiora doğru yüksek venöz basıncı olacağından, daha net klinik bulgu verir.

Santral venöz kateter uygulamalarına bağlı VKS tıkanıklıklarının sebebi, tekrarlayan ve uzun süreli travma ile ilişkili anormal yüksek akım sonucu gelişen, neointimal hiperplazidir. Akut stenozlarda, tromboz varken, kronik stenozlarda fibrozis öne çıkmaktadır (1-4). Kollateral venöz dolaşım yayılımı ve şiddetine bağı olarak, Stanford ve Doty (5), VKS tıkanıklığı için bir sınıflandırma önermişlerdir:

Tip I, VKS'da \%90'a varan darlık, azygos / sağ atriyal yolu açık ve antegrad akım mevcut (1)

Tip II, VKS'da \%90'dan fazla darlık, azygos / sağ atriyal yolu açık ve antegrad akım mevcut

Tip III, VKS'da \%90'dan fazla darlık ve kan akışı azygos venin tersi yönündedir

Tip IV, VKS 'de ve azygos ven de dahil, majör vena kava kollarının bir yada birkaçında tıkanıklık olması (Resim 2b)

\section{1. İzole Vena Kava Superior trombozun nedenleri}

İzole vena kava trombozun en sık nedeni, vena kava'da bulunan yabancı cisim varlı̆̆ı, santral kateter ya da 'pace-maker'dır. Superior vena kava tümörleri nadir olmakla beraber görülebilir. Behçet hastalığı da vena kava trombozuna neden olabilir (6).

\section{Benign Hastalıklar}

Benign bir tümör, mediastinal lenf bezi iltihabı veya fibrozan mediastinit, vena kava'ya bası yaparak, stenoza neden olabilir.

\section{a) Kronik Mediastinit}

Mediastenin lenfatik dokusundan gelişen skleroenflamatuar yanıt, vena kava superior da dahil olmak üzere mediastendeki tüm organlarda darlığı yol açar. Mediastinal fibrozisin üç ana nedeni vardır:

1) Tüberküloz, histoplazmozis veya norkadioza bağlı perinodular sklero-inflamatuar bir reaksiyon kronik mediastinit'in en sık nedenidir.

2) Akut mediastinit sonrası sekonder skleroza bağlı gelişebilir: özofagus perforasyonu, trakea cerrahisi, boyun apsesinin mediastinal yayılımı buna yol açabilir.

3) Methysergide (seratonin 5-HT antagonisti, migren profilaksisinde kullanıır) gibi bazı ilaçların uzun süreli kullanımı da mediastinal fibrozis nedenidir.

\section{b) Benign lenf bezi basıları}

Sarkoidoz veya tüberküloza bağı lenf bezleri vena kava superior sendrom nedenidir. Tanı mediastinoskopi ve/veya endobronşiyal biyopsi (EBUS) ile konur.

\section{c) Mediasten'in benign tümörleri}

Vena kava superior sendromuna en sık 'Planjon guatr' yol açar. Tanı, kademeli gelişen semptomlar, servikal guatr anamnezi, hastanın ileri yaşı ve ön üst mediastende trakeya'yı da baskılayan radyolojk görüntüler ile konur.

Bunun dışında timoma, germ hücreli tümörler veya timik kistler de benign VKSS nedenleridir.

\section{d) Arteriyal anevrizmalar}

Arkus aortanın veya dallarının aterosklerotik, sifilitik veya displastik anevrizmaları, direkt bası ile vena kava superior sendromuna yol açan en sık nedendir. Asendan aort veya supra-aortik arterlerin travmatik rüptürü de mediastinal hematom veya yalancı anevriz- 
ma şeklinde akut veya kronik vena kava sendromu'na neden olabilir.

\section{Malign patolojiler}

Mediastinal ve pulmoner maligniteler VKSS en sık nedenidir. Malign tümörler tanı ve tedavi sonuçları nedeniyle dört kısımda incelenir

a) Malign mediastinal adenopatiler

Mediastinal tümörler, anterosuperior mediastende sağ alt paratrakeal bölge ve sol innominat ven düzeyinde superior vena kavaya bası yaparlar. En sık nedenler arasında Hodgkin veya non-Hodgkin lenfoma ile akciğer kanserinin mediastinal metastazları yer alır. Lenf bezi biyopsisi ile tanı konur.

\section{b) Akciğer kanseri}

Akciğer kanseri hiler lenf bezi metastazı veya sağ üst lob tümörleri ile direkt lenf nodu metastazı veya azygos vene bası ile VKSS yapar. Bu tip olgularda vena kava superior rezeksiyon ve rekonstrüksiyonu gerektiren cerrahi yapılabilir.

c) Ön ve orta mediastenin solid tümörleri

Anterior ve orta mediasten tümörlerinin bir kısmı, vena kava superior rezeksiyon ve rekonstrüksiyonu gerektirir. Genellikle tüm innominat-vena kava, perikard, sağ frenik sinir ve muhtemelen sağ üst lob ve orta lobu içine alan geniş ekstensif bir cerrahi yapilır. Nitekim bu tümörler hemen her zaman trakea ile beraber arteriyal seviyede arkus aorta, brakiosefalik arter ve sol common karotid'e komşudur.

$\mathrm{Bu}$ anatomik lokasyonda üç tip tümör yer alır:

Myastenia gravis ile ilişkili veya ilişkisiz invazif veya malign timoma, cerrahi için endikasyondur. Adjuvan radyoterapi ile olguların yarısından fazlasında 5 ve 10 yıllık sağ kalım görülür.

Germ hücreli tümörler çok nadirdir ve alfafetoprotein (AFP) ve koryonik gonadotropin (HCG) gibi biyolojik belirteç ile tespit edilebilir.
Hodgkin lenfoma gibi bazı lenfoma tipleri de kesinlikle antero-superior mediasten ile sınırlıdır.

Bazen de, küçük hücreli yada indiferansiye kanser ile viseral organ metastazları da görülür.

\section{d) Neoplastik mediastinit}

Neoplastik mediastinit özellikle meme kanserine sekonder olabilir. Tanı biyopsi ile mediastinoskopi sırasında konur.

\section{Klinik}

Vena kava superior sendromu genellikle birkaç hafta veya ay içinde oluşur. Basıya bağlı, boyun ve üst hemitoraksta kollateral venöz sistemi gelişir. Basının ve tıkanıklığın derecesine göre klinik bulgular görülür (Tablo 2). Belirtiler yüzde ödem, yatar pozisyonda artan nefes darlığı, öksürük, anormal görme, ortopne, ses kısıklığı, stridor, mide bulantısı, baş ağrısı, baş dönmesi veya bayılma olabilir. Stridor, larenks ödemini gösterir, konfüzyon ve dikkatli olma halinin zayıflaması ise serbral ödem bulgusudur.

Fizik muayenede burun içi, yüz, göz kapakları ve supraklavikular ödem ile siyanoz, dilate jugular ven ve göğüste kollateral sirkülasyon ortaya çıkarabilir $(1,2)$. Hastanın kolları baş seviyesinin üzerine kaldırılarak 'Pemberton manevra'sı yapılır. Hastada fasiyal pletore (yüzün ve boynun venöz staza bağlı pembe-mavi renk değişimi) ya da başta konjesyon, baş dönmesi yada sıkıntı hissi oluşması ile test pozitif kabul edilir. Bu retroklaviküler bölgede artmış venöz basıncı gösterir. Yüz ödemi ve siyanoz kötüleşebilir.

Geçmişte, VKSS tıbbi acil bir durum olarak ele alınmaktaydı. Oysa günümüzde larenks ya da serebral ödem dışında acil olmadığı yolunda yaygın bir görüş vardır (2). VKSS'lu hastaların klinik değerlendirilmesinde standart bir yaklaşım yoktur. Son zamanlarda ortaya atılan ve pek kabul görmeyen bir yaklaşım, hastaları asemptomatik (evre 0), hafif (evre 1), orta (evre 2), ağır

Tablo 2. Vena kava superior sendromunda stenoz derecesine yada tıkanıklığa bağlı semptomlar

\begin{tabular}{|c|c|c|}
\hline Başlangıç (Tip I) & Orta (Tip II ve III) & Geç (Tip IV) \\
\hline \multirow[t]{2}{*}{ Yüzde hafif şişme } & $\begin{array}{l}\text { Yüzde kızarma, artmış } \\
\text { ödem, yüzde eritem }\end{array}$ & $\begin{array}{l}\text { Santral venöz sistem: Artmış jugular venöz distansiyon, } \\
\text { taşikardi, azalmış kan basıncı, periorbital siyanoz } \\
\text { ve dilate belirgin gövde venleri }\end{array}$ \\
\hline & $\begin{array}{l}\text { İlerliyici boyun ve gövdede } \\
\text { şişme ve ödem }\end{array}$ & Solunum: Öksürük, dispne, ses değişikliği, taşikardi \\
\hline $\begin{array}{l}\text { Periorbital konjuktival } \\
\text { ödem }\end{array}$ & $\begin{array}{l}\text { Kollar, parmak ve ellerde } \\
\text { şişme }\end{array}$ & $\begin{array}{l}\text { Santral Sinir sistemi: Başağrısı, konfüzyon, } \\
\text { anksiyete, görme bozuklukları }\end{array}$ \\
\hline \multirow[t]{2}{*}{ Sabah görülen bulgular } & $\begin{array}{l}\text { Islak gözler ve kızarık } \\
\text { konjuktiva }\end{array}$ & Gastrointestinal: disfaji \\
\hline & $\begin{array}{l}\text { Burun kanaması ve yüzde } \\
\text { eritem }\end{array}$ & \\
\hline
\end{tabular}


(evre 3), yaşamı tehdit edici (evre 4) ya da fatal (evre 5) olmak üzere sınıflandırmıştır (7). Serebral ödem, larenjiyal ödem, stridor ve hemodinamik bozukluk evre 3 ya da 4 VKSS olarak tanımlanmıştır. Hastalarda tanı konularak uygun tedaviye başlanılmalıdır.

\section{Tanısal yaklaşım}

Vena Kava Superior Sendromunun altta yatan nedeni ve teşhisi çok önemlidir (8):

1. VKSS'a yol açan bazı hastalıklar medikal tedavi ile düzelebilir

2. VKSS'lı kanser hastaları sendromdan çok altta yatan malignansi nedeni ile ölürler

3. Benign hastalıklar VKSS'un \%5'inden sorumludur.

Vena kava superior sendromu klinik bir teşhistir. Bu sebeple ayırıcı tanıda bazı özel durumları bilmek gerekir.

\section{'False' vena kava sendromları}

a) İzole sol innominat ven trombozu

İzole sol innominat ven trombozu, anterior mediasten tümörleri ile birlikte sıkça görülür. Kontralateral venöz sistemi ile zengin anastomoz gösterir. Sol innominat venin, mediastinal tümör ile birlikte cerrahi eksizyonu, hasta da bir komplikasyona yol açmaz.

b) Bilateral aksiller-subklavyan flebiti

Torasik outlet sendromu'na bağlı gelişen bilateral aksiller-subklavyan flebiti, gerçek VKSS'dan servikosefalik kollateral yokluğu ile innominate ven ve vena kava superior'un normal oluşu ile ayırt edilmelidir.

\section{c) Arterio-venöz fistül}

Vena kava superior sistemindeki bir arterio-venöz fistül, VKSS'unu taklit ederek kardiyak ve nörolojik semptomlara yol açar; fistül yanında sistolik-diyastolik bir üfürüm duyulur. Fistül sıkça servikal veya mediastinal travma sonrası görülür.

\section{Vena Kava Superior Sendromu Tanısı \\ Tanısal Yaklaşımlar}

Doku tanısı altta yatan malignansiyi belirlemek için şarttır. Akut hava yolu obstrüksiyonu ya da artan nörolojik problemler yok ise, doku tanısı olmadan bir tedaviye başlanması önerilmez. Diğer taraftan hastaların genel durumları çok hızlı bir şekilde bozulacağından, teşhise yönelik girişimler hızlı yapılmalıdır. Tedavi, altta yatan hastalığa bağlı olarak ya küratif ya da palliatif olarak planlanacaktır. Tanı öncesi yapılacak radyoterapi, kemoterapi ve/veya steroid kullanımı, histolojik teşhisi belirsizleştirebilir. Radyoterapi, biyopsilerin \%42'sini belirsizleştirebilir (9). Dikkatli klinik muayene çok önemlidir, özellikle skalen lenf bezi varlığında daha invazif bir girişimden ziyade basit bir biyopsi ile tanı konur.
Rutin tanı metodları akciğer grafisi, toraksın bilgisayarlı tomografisi (BT) ve üst ekstremite venografisidir. Sonuçlar genellikle bronkoskopi, EBUS, biyolojik belirteçler (CEA, AFP, HCG) veya mediastinoskopi ile konur.

\section{a) Akciğer grafisi}

Akciğer grafisinde genellikle büyük anterior mediastinal tümör veya mediastene invaze bronşial tümör görülür.

\section{b) Bilgisayarlı tomografi (BT)}

BT, tümörün vena kava superior ile olan ilişkisini gösterir. Retrokaval tümör görüntüleri genellikle mediastinal lef bezi metastazı, prekaval veya retrosternal görüntüler de sıklıkla mediastenin solid tümörleridir.

\section{c) Üst ekstremite venografisi (Resim 1)}

Venografi'de radionüklit Tc-99 $\mathrm{m}$ kontrast enjeksiyonu, her iki üst ekstremite damarlarına aynı anda yapııı. Böylece tıkanıklığın niteliği anlaşıır:

- Tek dairesel darlık mediastinit veya kanser nedenidir

- Bası benign veya malign bir tümörle oluşur

- Tam tromboz, internal jugular ven ve kavo-atriyal kavşak içinde değerlendirilir.

\section{d) Bronkoskopi}

Endobronşiyal tümör tanısı bronkoskopi ile konur. Aynı zamanda mediastinal tümör varlığında trakeanın invazyonu değerlendirilir. Bronkoskopinin teşhisteki başarısı \%50-70 transtorasik iğne aspirasyonunun $\% 75$ 'tir $(10,11)$.

\section{e) Tümör belirteçleri}

Biyolojik tümör belirteçleri (AFP, HCG, CEA) rutin olarak alınmalıdır. İlk ikisinin yüksek çıkması malign germ hücreli tümör lehine yorumlanır.

\section{f) İyot sintigrafisi}

Tiroid tümör şüphesi olduğunda yapılır.

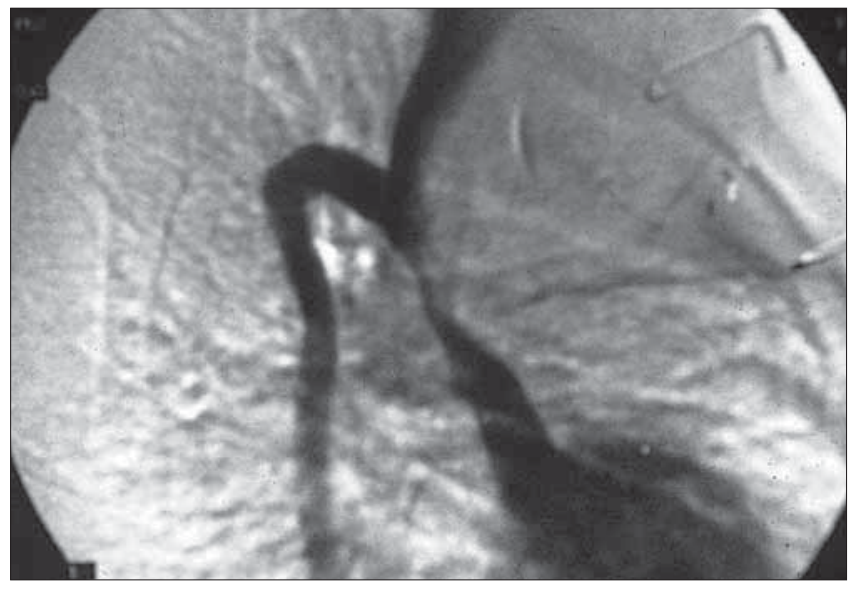

Resim 1. Venografi'de vena kava superiordaki darlık görülmekte 


\section{g) Mediastinoskopi}

Mediastinoskopi, vena kava superior sendromunda kontraendike değildir ve etyolojiyi ortaya koymada çok yaralıdır. Gerek lenf bezi gerekse kitleden alınacak biyopsiler ile tanı konur. Tanı koyma başarısı \%90 ve \%100'lere ulaşır $(12,13)$. Kanama ve enfeksiyon gibi risk oranı \%0-7'dir $(14,15)$.

h) Endobronşiyal Ultrasonografik Biyopsi (EBUS)

VKSS'lu hastalarda EBUS kullanımı ile ilgili bir bilgi şu an için yoktur. Randomize çalışmalar EBUS'un transbronşiyal iğne aspirasyonlarından üstün olduğunu göstermiştir (16). Bu sebeple EBUS, özellikle mediastinoskopi yapmanın mümkün olmadığı durumlarda kullanılabilir (2).

\section{Tedavi}

Vena Kava superior sendromunun tedavisi altta yatan kanser etyolojisi, hastalığın yaygınlığı, semptomların şiddeti ve hastanın prognozuna bağlıdır (2). VKSS'lu bir hastanın ortalama sağ kalımı ortalama 6 aydır (1.5-9.5 ay) (17). Tedavi hem altta yatan malignansiye hem de obstrüksiyon semptomlarının geriletilmesine yönelik olmalıdır. Tedavi algoritmaları randomize çalışmalardan çok vaka sunumlarına dayandırımaktadır.

Vena Kava Superior Sendromlu hastalarda tedavi seçenekleri destek tedavi, radyoterapi (RT), kemoterapi (KT) ve stent kullanımıdır. VKSS olan kanser hastalarında, genelde unrezektabl bir tümör varlığı söz konusu olduğundan cerrahi tedavi akla gelmez. Mediastinal lenf nodu pozitif VKSS'lu KHDAK'li seçilmiş hastalarda, neoadjuvan tedavi sonrası cerrahi tedavi akla gelebilir.

\section{Semptomatik Tedavi}

Medikal tedavi ve destek bakım ilk adımdır. Bu yaklaşımın etkinliği ile ilgili bir bilgi olmamakla beraber, düşük risk ile VKSS semptomları başlangıçta azaltıIır. Oksijen desteği, gövde ve baş-boyun bölgesinde ödemi azaltacak sıvı kısıtlamaları, başın kaldııılması ve diüretik kullanımı erken dönemde etkindir. Yaşamı tehdit edici hava yolu obstrüksiyonları ve/veya serebral ödem'in erken tanısı önemlidir. VKSS ile görülen serebral ödemin tedavisi literatürde belirtilmemiştir. Başın yükseltilmesi, hiperventilasyon ve mannitol kullanımı faydalıdır. Steroid kullanımı ödemi azaltmak için önerilmektedir (18). Buradaki en önemli soru, steroid kulanımının özellikle lenfoma tanısı koymada sorun çıkartabilmesidir $(19,20) .107$ hastalık bir çalışmada, steroid ve diüretik kullanılan ve kullanılmayan hastalarda \%84'lere varan klinik düzelme olduğu bildirilmiştir (21). Bununla beraber, havayolu ödemi olan sempto- matik hastada steroid kullanımı etkilidir. Önerilen doz günde $2 \mathrm{kez}$ oral 'dexamethasone $4 \mathrm{mg}$ ' yada oral 4 kez 4 mg/gün'dür (2). Kronik steroid kullanımı kendi komplikasyonlarına yol açacağından, steroid'in sadece başlangıçta kullanılması gerektiği akıldan çıkartılmamalıdır.

Malignansiye bağlı VKSS'da pulmoner emboli ya da tromboemboli görülme sıklığı \%38'dir (22). Tromboz varlığı gösterilen olgularda, antikoagulasyon tedavi başlanmalıdır. Doku tanısı ile tanı konulduktan sonra küratif veya palliatif tedavi kararı verilmelidir.

\section{Radyoterapi}

Radyoterapi (RT) malignansi nedeni ile gelişen VKSS'da etkili bir tedavidir. Radyoterapi KHDAK nedeni ile VKSS olan hastaların \%75'inde iyileşme sağlamaktadır (20). Tedaviye yanıt 7-15 günde olmakla beraber, ilk 72 saatte bile bir cevap görülebilir.

\section{Radyoterapi Kontraendikasyonları}

RT'nin göreceli kontraendikasyonları vardır bunlarda aynı bölgeye uygulanmış RT, skleroderma gibi bağ dokusu hastalıkları ve sarkom gibi radyorezistan tümörler. RT tedavisi tümörün hücre tipi ve hangi tip tedavi yapılacağı ile direkt ilişkilidir (Resim 2). Tedavi sırasında oluşabilecek komplikasyonlar dikkatli gözlenmelidir. Stent yerleştirilmesi ya da antikoagulasyon uygulaması gerektirecek durumlar görülebilir.

\section{Kemoterapi}

Lenfoma, küçük hücreli akciğer kanseri ve germ hücreli tümörler kemoterapiye duyarlıdır. RT bu hastalıklarda erken yanıt için kullanılabilir, fakat uzun dönem sonuçları iyi değildir ve KT yapılamıyacak hastalarda uygulanır $(20,23)$. KT ile Non-Hogkin lenfomalı hastaların \%80'i ve küçük hücreli akciğer kanseri hastalarının \%77'sinde klinik semptomlar geriler $(20,23)$. Tedaviye yanıt 7-15 gün içerisinde görülür (17).

\section{Endovasküler Stent}

Vena kava superior sendromu olan hastalarda endovasküler stent kullanımı venöz dönüșü sağlayarak hızlı bir klinik düzelme sağlar (Resim 3). Bu düzelmenin 24-72 saat'te olduğu bildirilmiştir (24-26). Endovasküler girișim özellikle doku tanısı olmayan acil hastalarda yada geçirilmiş RT öyküsü olan yada kemo ve/veya radyoterapiye dirençli hastalarda yapıIır. Bunun yanınsıra, endovasküler stent uygulaması VKSS'lu hastalarda ilk tedavi yaklașımı olarak da bildirilmiştir (27-29). Stent uygulaması sonrası hastaya küratif tedavisi bașlanır.

Ayrıca VKS'da stent varlığı cerrahi bypass'ı engellememektedir (30). 

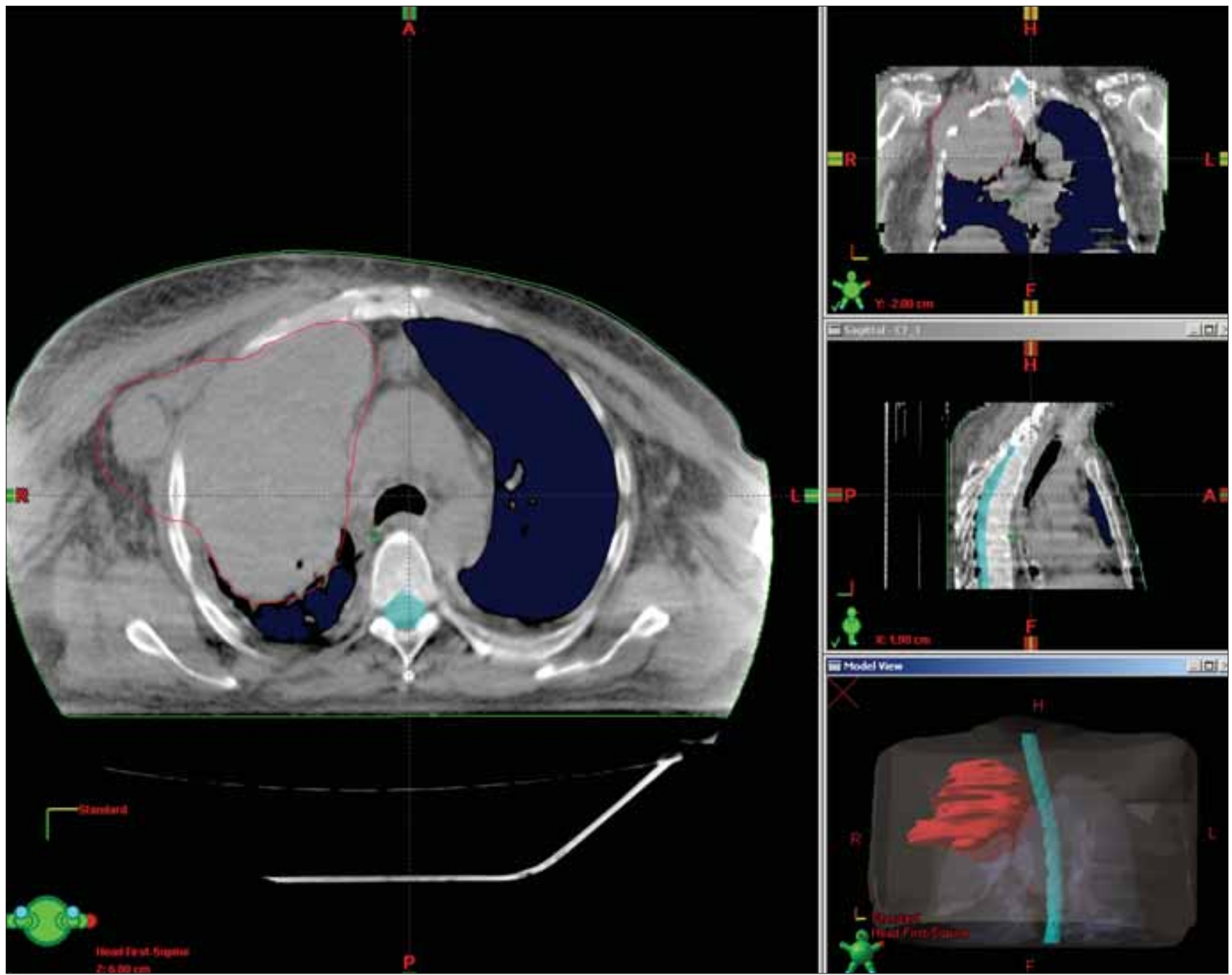

Resim 2. Vena kava superior sendromuna yol açan, sağ üst lobda küçük hücreli akciğer kanseri olgusunda küratif radyoterapi planlanması

\section{Cerrahi tedavi}

Günümüzde, yaşam beklentisi altta yatan hastalığa da bağlı olarak arttığından, radikal cerrahiler olmak üzere bir çok tedavi seçeneği kullanılmaktadır. Cerrahi revaskülarizasyon, rezektabl lokal ileri küçük hücreli dışı akciğer kanserlerinde seçilmiş hasta grubunda başarılı olmaktadır. Bundan başka, özellikle benign VKSS hastaları tedavisi cerrahi'dir; uzun dönemde bu daha etkilidir (1).

Vena kava superior'un rezeksiyonu ve rekonstrüksiyonu gerektiğinde bazı sorular ile karşılaşılmaktadır (31-33): Graft materyalinin tipi, VKS klemplenmesin hemodinamik etkileri, graft enfeksiyonu, uzun dönem sağ kalım ve uzun dönem graft açıklığı (patency).

\section{Endikasyonlar}

İlk tedavi alternatifi olarak cerrahi, tanısı konmamış, anterior mediastinal tümör, lenf bezi negatif KHDAK ve benign VKSS'lu asemptomatik, Tip I yada II VKSS'lu hastalarda akla gelmelidir (Tablo 3) (34). Cerrahi ile hem tanı için yeterli doku alınacak, hem de benign nedenler nedeni ile oluşan VKSS ortadan kaldırılacaktır. Hemodinamik açıdan ele alındığında, primer cerrahi rezeksiyon ve revaskülarizasyon sefalik venöz yatağın tamamı ile tıkalı, proksimal venlerin anormal venöz duvara sahip olduğu tip III ve IV olgularda kontraendikedir. Çünkü, gelişmiş olan kollateral venöz sirkülasyonu, VKS'a konulacak graft'ta tromboza yol açacaktır. $\mathrm{Bu}$ durumda jugular yada aksiler venler kullanılarak yapılacak proksimal anastomozlar ile tıkalı VKS'nin bypass edilmesi ilk tedavi seçeneğidir. Bu revaskülarizasyon tekniklerinin yüksek oranda tromboz riski taşıdığı unutulmamalıdır.

\section{Preoperatif Değerlendirme}

Vena Kava superior invazyonu olan küçük hücreli dışı akciğer kanseri rezeksiyonu ve rekonstrüksiyonu sonrası ortalama sağ kalım 19 ay ve 5 yıllık sağ kalım 

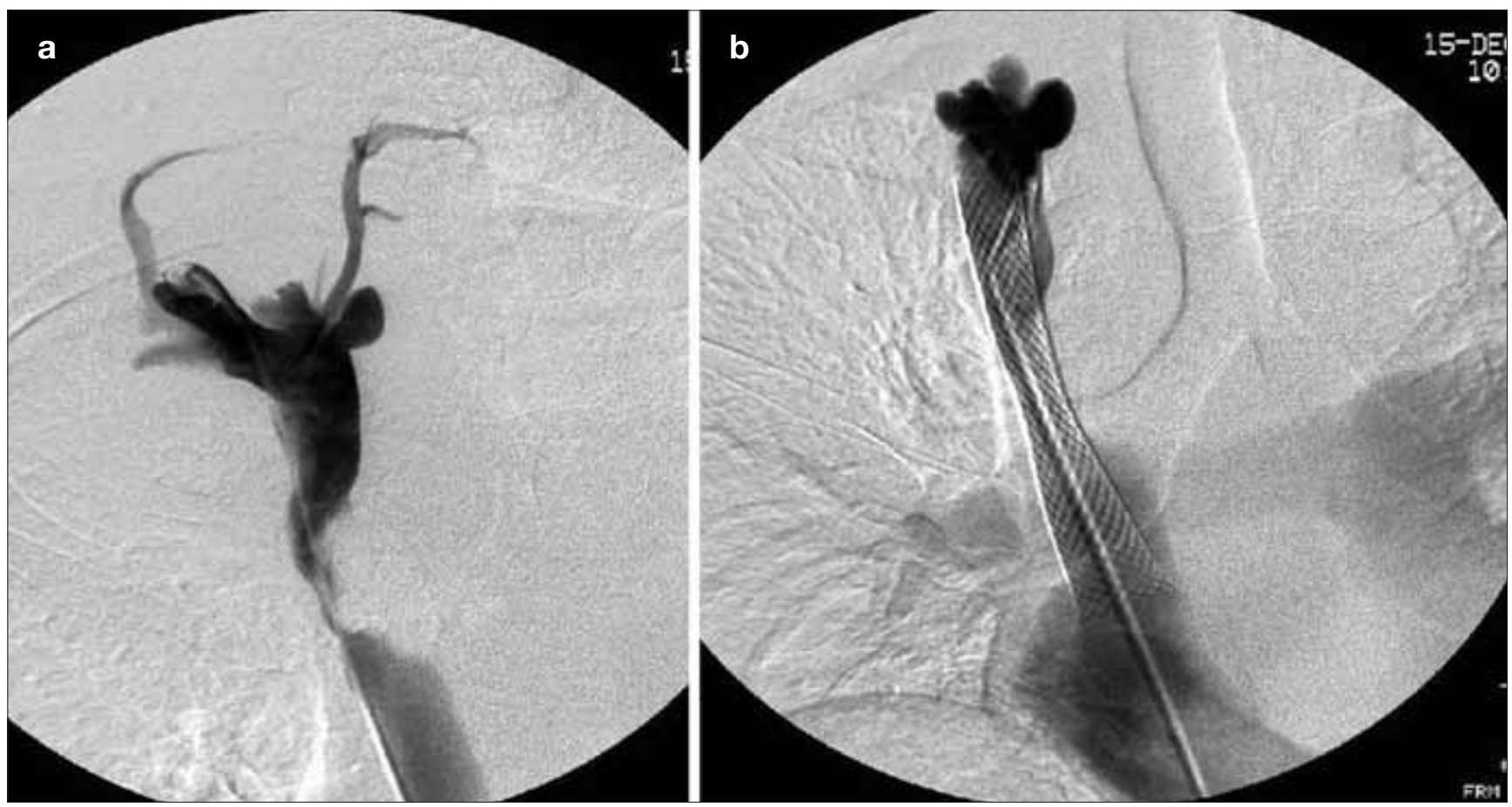

Resim 3. Vena kava superior sendromuna yol açan sağ üst lob tümörlü bir olguda vena kava superiora konan endovasküler stent a) öncesi, b) sonrası radyolojik görüntüler

Tablo 3. Vena kava superior sendromunda cerrahi endikasyonlar ve kontraendikasyonlar (1)

\begin{tabular}{|ll|}
\hline Endikasyonlar & Kontraendikasyonlar \\
\hline $\begin{array}{l}\text { Malignansi } \\
\text { Operabl KHDAK }\end{array}$ & VKSS'a yol açan unrezektabl malignansi \\
$\begin{array}{l}\text { Anterior mediastinal tümörler } \\
\text { Primer VKS tümörleri }\end{array}$ & N2 hastalıklı KHDAK ve/yada pnömonektomi gerektiren KHDAK \\
& Tip III VKSS \\
Vasküler & Proksimal venlerde anormal venöz duvar \\
$\begin{array}{l}\text { Primer sakküler anevrizma } \\
\text { Primer malformasyonlar }\end{array}$ \\
Benign nedenler & Pacemaker-induced VKSS \\
\hline KHDAK: Küçük Hücreli Dişı Akciğer Kanseri, VKS: Vena Kava Superior, VKSS: Vena Kava Superior Sendromu \\
\hline
\end{tabular}

\% 29.4 olarak bildirilmiştir (35). Bu oran NO/1 hastalıkta \%37.5'lara ulaşmıştır. Bu sebeple cerrahi planlan hastalarda ameliyat öncesi hastalığın yayılımı çok iyi değerlendirilmelidir. Tüm hastalara venöz obstrüksiyonu tam olarak ortaya koymak için bilateral kol venografisi yapılmalıdır. Sistemik venöz anatomisi anjiyografi ile dikkatli bir şekilde incelenmelidir. Özellikle karşı taraftaki VKS (persistant sol VKS) ve azygos ya da vena kava inferior ile devamlılık gösteren hemiazygos varlığı ortaya bu şekilde konur. Subklavyen venlerin ultrasonografi ile incelenmesinde ani 'sniff-koklama' manvevrası ile venlerin normal kapanmasının olmadığı görülür. Baryum grafileri özofajyel varisleri gösterir.
Ekokardiyografi trombüsün sağ atriyum ile olan ilişkisini ortaya koyar. VKS'un bir akciğer kanseri ile invazyonunu gösteren radyolojik bulgu BT'de terminal VKS posterior duvarının invazyonu ve pulmoner anjiyografide üst lob'un perikard içersinindeki mediastinal dalının amputasyonudur (Resim 4). VKS'un kros-klemp sırasındaki toleransını belirlemek için de beyin incelenir.

\section{Intraoperatif Monitorizasyon}

Rutin bir toraks cerrahisi sırasında yapılan tüm monitorizasyonlar bu hastalar için de gereklidir. Ancak VKS klempleneceğinden, femoral ven ve arterlerden açılacak damar yolları ile vena kava inferiora santal 


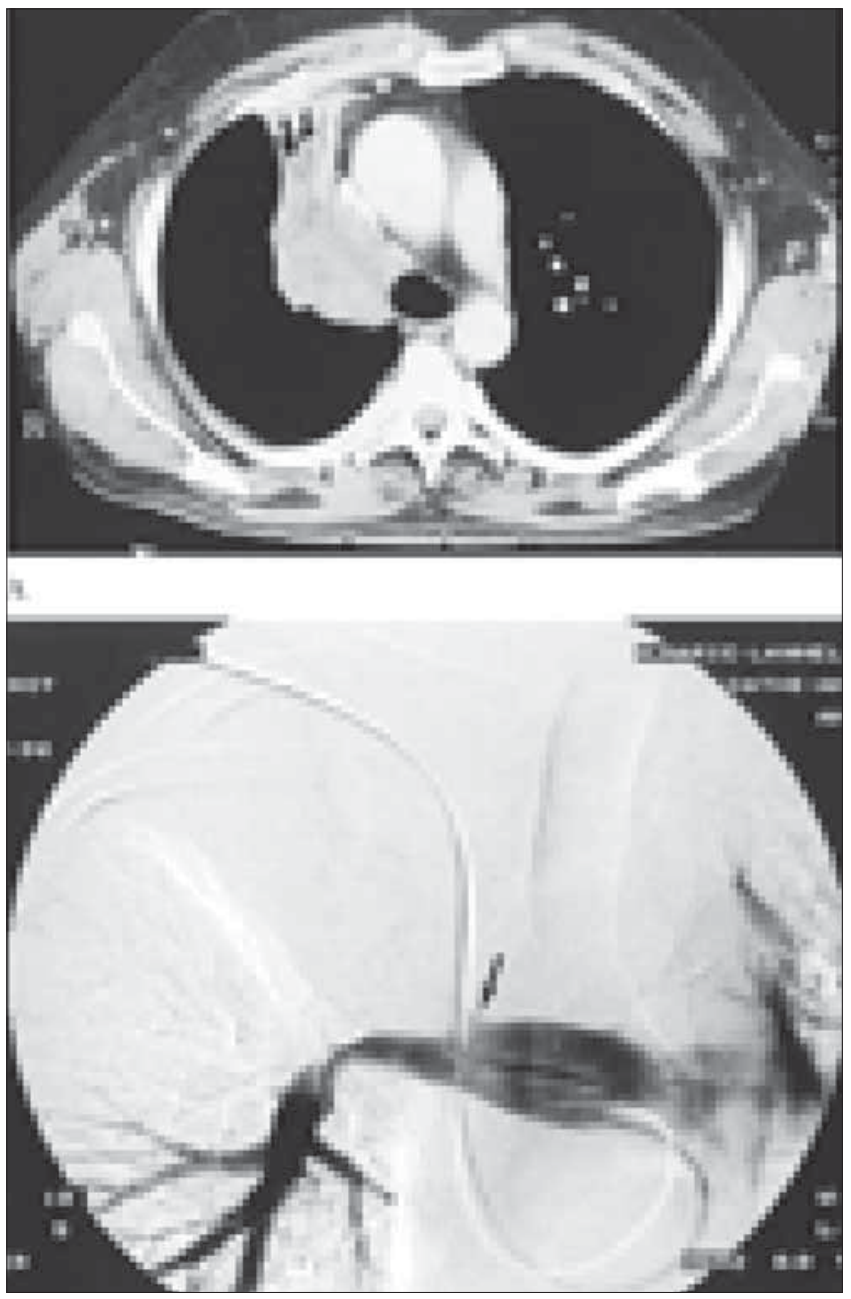

Resim 4. Toraks BT'de terminal Vena kava superiorun posterior duvarının invazyonu ve pulmoner anjiyografide üst lob'un perikard içersindeki mediastinal dalının amputasyonu görülmekte

kateter yollanır. Ayaktan açılacak ikinci bir damar yolu da VKS klemplenmesi sırasında volüm ihtiyacını yüklemek amacı ile hazır tutulur.

\section{Cerrahi Yaklaşım}

Akciğer kanserlerinde sağ torakotomi, mediastinal tümörlerde ise medyan sternotomi insizyonları kullanilır.

\section{a) Dekompresyon}

Gerek kompresyon gerekse de konstriksiyon'a (sıkıştırma) bağlı, tümör invazyonu olmadan oluşan Vena kava superior sendromu, kompresyon ortadan kaldırıldığında kaybolur. Bu nedenle planjon guatr veya arkus aorta ve dallarının düz greft anevrizmalarının eksizyonu ile kaval sirkülasyon rahatlatılarak normal dolaşım sağlanır. Enflamatuar lenf bezleri ve özellikle tüberküloz komşu organlara yapışıklıklar nedeni ile genellikle tam rezeke edilemez.

\section{b) Tromboembolektomi}

Mekanik (36) ya da cerrahi venöz tromboembolektomi, katetere bağlı kısmi VKS trombozlarında yabancı cismi veya kateteri çıkarmak ve akut pulmoner emboli riskini azaltmak için endikedir. Pace-maker nedeni ile oluşan VKSS'da balon venoplasti ve/veya "selfexpandable" ya da "balon-expandable" stentlerin kullanımı artmıştır (37).

\section{c) Anjioplasti}

Vena kava superiorun \%30'undan azı tutulmuş ise, venin kısmi rezeksiyonu ve defektin primer ya da perikard veya bir ven ile "yama-plasti" yapılarak kapatılması mümkündür.

\section{d) Rezeksiyon ve rekonstrüksiyon}

Vena kava superiorda \%30'dan fazla bir tutulum var ise, kava'nın total rezeksiyon ve anastomozu yapılmalıdır. Bunun için farklı materyaller önerilmiştir: Otolog perikard (38), 40-Fr stent etrafına sarılmış ve $12 \mathrm{~mm}$ çap ile sütüre edimiş safen ven (39), ve sentetik materyaller (40). Sentetik materyallerin aksine, perikard ve ven kolay hazırlanır ve kullanılır, enfeksiyon riski taşımaz, ve antikoagülayon tedavi gerektirmez. Venöz sistemde kullanılan Protez greftler arteriyel greftlere göre kolay oklüde olurlar. Hidrostatik basınç farkına karşı göreceli daha yavaş venöz akım, düşük intraluminal basınç ve venöz kollaterallerden kaynaklanan akım nedeni ile tıkanma sıkça görülür. VKS rekonstrüksiyonunda, sentetik 'polytetrafluoroethylene (PTFE)' vasküler greft tercih edilen ürün olmuştur. Açıklığını (patency) uzun süre koruyabilen tek sentetik materyaldir. Anastomuzu takiben, endotel hücreler ile epitalize olur ve ender komplikasyona yol açar. Son olarak kadavradan elde edilen 'ABOuyumsuz arteriyal homogreftlerde', rekonstrüksiyon için ortaya atılmıştır (1).

Sonuçta hangi metod kullanıırsa kullanılsın, amaç semptomları geriletmek, komplikasyon riskini azaltmak (enfeksiyon, santral sinir sistemi hasarları, respiratuar ödem ve stridor) ve Vena kavanın yüksek akımlı (7502000 mL/dk) uzun dönem açıklığının sağlanmasıdır.

\section{Vena Kava Superior klemplenmesi etkilerinin önlenmesi}

Tip I ve II VKSS olan hastalarda, VKS'un \%50'sinden azının klemplenmesi önemli bir hemodinamik soruna yol açmaz. 30-35 dakika klemplenme süresi kabul edilebilir ve tolere edilir $(31,40)$, fakat bunu aşan sürelerde venöz dolaşımın engellenmesi, fatal serebral ödem veya postoperatif nöroljik problemlere yol açabilir. Bu anlarda yapılacak manevralarla oluşabilecek hemodinamik sonuçlar engellenebilir. 


\section{Şantlar}

Sağ internal jugular ven yada brakiosefalik trunk ile sağ atriyum arasına konulacak intraluminal yada ekstraluminal şantlar sağ atriyuma venöz dönüşü sağlamakla beraber, VKS klemplenmesi ile ilgili zaman baskısını ortadan kaldırır, rekonstrüksiyon yada tam tamiri mümkün kılar, açık bir VKS klemplenmesi ile azalacak serebral sirkülasyon arteriovenöz gradienti nedeni ile oluşacak sistemik hipotansiyonu engeller, gövdedeki venöz hipertansiyon ve konjesyonu hemen azaltır (erken ekstübasyon ve sorunsuz bir postoperatif dönem sağlar) ve son olarak nöroljik komplikasyonları engeller.

\section{Kardiovasküler Tedavi}

Vena kava superior klemplenmesi kranial venöz hipertansiyon ve sistemik hipotansiyon yol açar. Bu da serebral kan akımını azaltarak nörolojik sonuçlar doğurur. Beyni korumak için, klemplemeden $30 \mathrm{dk}$ önce steroid verilmesi ve arteriyal basıncı normal tutmak için de yeterli sıvı ile norefinefrin verilmesi gerekir. Serebral kan perfüzyonunu $60 \mathrm{mmHg}$ üzerinde tutmak için, mean arteryal kan basıncı 'jugular bulb pressure'un en az $60 \mathrm{mmHg}$ üzerinde tutulur (örnek; 'jugular bulb pressure' $50 \mathrm{mmHg}$ yükseltildiğinde, mean arteriyal kan basıncı $110 \mathrm{mmHg}$ olur). Amaç, 'jugular bulb oksijen saturasyonu' \%50 üzerinde tutmaktır. Serebral kan volümünü azaltmak için hasta hafif hiperventile edilir.

\section{Venöz Klemplenme Süresini Kısaltma}

Ameliyat öncesi cerrahi strateji net ortaya konmalldır. Karinal yada proksimal pulmoner arter invazyonlu sağ KHDAK'de, ilk önce ameliyatın vasküler kısmı bitirilir. Bronş rezeksiyonu sırasında protezin bakteri ile direkt kontamine olması önlenmelidir. Her iki üst lobuda tutan mediastinal tümörde, ameliyat soldan sağa yapılır.

\section{Antikoagulasyon Tedavi}

İntravenöz (IV) heparin (0.5-1 mg/kg) klemp öncesi verilir.

\section{VKS Rekonstrüksiyon Tipleri}

\section{Tüm Vena Kavanın Replasmanı}

Vena kava replasmanı (trunk) her iki innominat ven sağlam olduğunda yapılır. Kanser olgularında kullanılan bu yöntemde düz, 'ringsiz' PTFE graft (No. 18 ya da 20) kullanılır. İlk önce proksimal anastomoz devamlı 5-0 prolen sütür ile yapılır, takiben distal anastomoz aynı şeklide bitirilir. Distal sütür bağlanmadan önce, proksimal klemp açılır, protez heparinli solüsyon ile yıkanır ve içindeki hava boşaltıır. Sonra distal klemp açılır ve anastomoz bitirilir. Protezin boğum yapmasını ve katlanmasını engellemek için distal anastomoz belli bir direnç altında yapılır. En sonunda graft pariyetal plevra ile korunur.

\section{Sol İnnominat Venden Revaskülarizasyon}

$\mathrm{Bu}$ işlem kesinlikle median sternotomi ile yapılır ve 'ringli' PTFE graft (No. 12 yada 13) gerektirir. Bu anastomozda kullanılacak protez biraz uzun olacağından, ve sternotomi kapatılmasını takiben graftin katlanma riski bulunduğundan, ringli graft kullanılması şarttır.

\section{Sağ İnnominat Venden Revaskülarizasyon}

No. 12 ya da 14 ringli graftler, hem açıklık hemde postoperatif fibrozise bağlı basıyı engelledikleri için tercih edilir. Proksimal güdük kısa olduğundan anastomozu zordur ve ilk yapılmalıdır.

\section{Her İki İnnominat Venden Revaskülarizasyon}

Bu teknik genelde kullanılmamaktadır. Çünkü her graftten gelecek kan akımı tek revaskülarizasyondan az olmakta ve buda tromboze neden olmaktadır.

\section{Postoperatif Bakım}

Hastalarda yakın takip edilir. VKSS riskini azaltmak için baş ve gövde yüksek tutulur. $1-2 \mathrm{ml} / \mathrm{kg}$ 'dan Heparin başlanır ve bu oral antikoagulasyona geçilerek hasta coumadin veya aspirin ile taburcu edilir.

\section{Vena Kava Rezeksiyon ve Rekonstrüksiyon Komplikasyonları}

\section{Graft Anastomozu}

Postoperatif dönemde BT çekilerek anastomoz değerlendirilir. Ven genellikle, tüm transvers çapıyla grafte birleşeceğinden, proksimal anastomozda bir darlık görülmez. Buna karşılık anastomoz darlığı, anastomoz proksimal'indaki venin intraoperatif aşırı diseksiyonu ile ilişkilidir. Postoperatif dönemde aşırı venöz uzunluk veya rotasyon belirlendiğinde, cerrahi düzeltme önerilmektedir. Fibrozis sonrası görülen darlık anjioplastik dilatasyon yada stent ile düzeltilir.

\section{Graft Trombozu}

Postoperatif erken bir komplikasyon olan graft rombozu mekanik tıkanma yada yanlış endikasyon ile ilişkilidir. En önemli sonucu akut klinik VKS sendromu oluşturmasıdır ki bu da geri dönüşümlü beyin hasarı veya pulmoner emboliye yol açar.

\section{Graft Enfeksiyonu}

Graft enfeksiyonu tüm vasküler protez operasyonlarında görülme intimali olan ciddi bir risk'tir. VKS replasmanlarında, hava yolu açık, bronşiyal ve akciğer rezeksiyonu yapıldığında, neoadjuvan kemoradyote- 
rapi sonrası cerrahi olgularda enfeksiyon riski artmaktadır. Enfeksiyon kendini mediastinit, ampiyem yada septisemi olarak gösterir. Tedavi sistemik sepsis olup olmamasına bağlıdır. Ağır septik şok yok ise, protez omentoplasti ile korunabilir. Hasta sepsiste ise, graftin çıkartılması gerekmektedir.

\section{PROGNOZ}

Prognoz tamamı ile altta yatan hastalığa bağlıdır ve tedavi edilmeyen olgularda 6 haftalık bir yaşam bildirilmiştir (1). KHDAK hastalarda VKSS olduğunda ortalama sağ kalım 6 ay, 1 yıllık sağ kalım \%35 ve küçük hücreli akciğer kanserinde \%18'dir $(20,22$, 43). Son yıllarda cerrahi teknik, anestezi ve yoğun bakım şartlarının ilerlemesi ve modernizisayonu ile vena kava superior rezeksiyonu gerektiren malign hastalıklarda \%15-56 seviyesinde 5 yıllık sağ kalımlar bildirilmiştir (Tablo 4) (31, 35, 44-49). Buradaki en önemli kriter olarak N2 hastalık olmaması ve cerrahi olarak R0-komplet rezeksiyon yapılabilmesi oluşturmaktadır (35).

VKSS benign hastalıklarının cerrahi tedavisi uzun dönem sonuçları ile etkindir. Endovasküler tedaviler kısa dönemde etkindir, fakat tedavi sonrası sıkça balon dilatasyon gibi girişimlere gereksinim duyulur. Endovasküler girişim geçirmiş hastalar cerrahi için bir kontraendikasyon oluşturmaz, hatta kimi cerrahlar bunun anatomisi uygun hastalarda ilk tedavi seçeneği olmasını önermektedir. Başarısız endovasküler girişim geçiren hastalarda vena kava superior'un cerrahi rezeksiyon ve rekonstrüksiyonu yapılır.

\section{SONUÇ}

Vena kava superior obstrüksiyonu tedavisi durumun akut oluşu ve altta yatan etyolojiye göredir. Malignansi nedeni ile olan VKSS tedavisinde medikal tedavi, diüretikler, kortikosteroidler, başın yukarda tutulması ve takiben tümör tipine bağlı olarak kemoterapi yada radyoterapi başlanır. Özelikle tedaviye yanıt vermemiş, hastalığı nüks etmiş yada uygulanabilir kemoterapi yada radyoterapi tedaviler bitmiş semptomları ortaağır yada hızlı kötüleşen hastalarda anjiyoplasti ve stent uygulaması endikedir. Günümüzde malignansiye bağı ıKSS'da obstrüksiyon semptomlarını geriletmek ve hastanın yaşam kalitesini düzeltmek için endovasküler girișimlerin kullanılması tedavinin ana unsuru haline gelmiştir. VKSS olan malignansi hastalarında 6 aydan az bir yaşam beklentisi vardır, bu hastalarda endovasküer tedavi yararlı olmaktadır.

Bununla beraber, VKS obstrüksiyonlarında cerrahi tedavi seçilmiş operabl ön mediastinal tümör yada vena kava superioru invaze eden ve pnömonektomi gerektirmeyen eden sağ taraflı KHDAK'de komplet rümör rezeksiyonunda bir rolü vardır. Vena kava superiorun minimal invazyonlarında primer defektin kapatılması ya da otolog perikard yada venöz yama-plasti; majör invazyon varlığında ise vena kavanın otolog perikard, safen ven graftleri ve sentetik materyaller ile rezeksiyon ve revaskülarizasyonu yapılır. Prostetik materyallerin aksine, otolog perikard ve ven elde edilmesi ve kullanımı kolaydır, enfeksiyon riski taşımaz ve antikoagulasyon tedavi gerektirmez. Hangi metod kullanılırsa kullanılsın, amaç semptomları geriletmek, komplikasyon riskini azaltmak (enfeksiyon, santral sinir sistemi hasarları, respiratuar ödem ve stridor) ve VKS açıkığının sağlanmasıdır.

Tıkalı olmayan VKS'un 35 dakikayı aşan klemplenmesi, fatal serebral ödem yada postoperatif nörolojik defisite yol açar, bu sebeple intraluminal yada ekstraluminal şantlar ile yeterli kardiovasküler destek, medikal tedavi ve antikoagülasyon ile morbiditeyi engeller.

Malign olmayan VKS tıkanıklığı venöz kollateral gelişimi nedeni ile sinsi başlar. Tedavi altta yatan etyolojiye bağlıdır ve bir çok vakada antikoagulasyon tedavisi hastayı rahatlatır. VKS tıkanıklığının artması ile görülen

\begin{tabular}{|lcccc|}
\hline \multicolumn{5}{|l}{ Tablo 4. Vena kava superior rezeksiyonu yapılan malign tümörlerde prognoz } \\
\hline Yazar & $\mathbf{n}$ & Morbidite (\%) & Mortalite (\%) & 5-Yıl sağ kalım (\%) \\
\hline Thomas (46) & 15 & 20 & 7 & 24 \\
Dartevelle (33) & 14 & 21 & 7 & 31 \\
Spaggiari (47) & 25 & 36 & 12 & 29 \\
Spaggiari (48) & 109 & 39 & 14 & 15 \\
Spaggiari (49) & 15 & 23 & 14 & 57 (3 y) \\
Yıldızeli ve Dartevelle (37) & 39 & 10.3 & 7.7 & 34.7 \\
Piquet (50) & 24 & 17 & 12 & 35 \\
Lanuti (51) & 17 & 63 & 5 & 56 \\
\hline
\end{tabular}


dekompansazyon semptomları stenoz yada kompresyonun kaldırıması ile geriler. Bu da cerrahi tamir, greft yada tıkalı VKS'ı bypass ile sağlanır. Cerrahi, benign VKS obstüksiyonlarında ilk tedavi seçeneğidir. Bu hastalarda stentin rolü kesinleşmemiştir.

Endovasküler tekniğin artan başarısı ve kabul görmesi ile yakın gelecekte benign ve malign VKS tıkanıklıklarında daha yaygın uygulanabileceği aşikardır.

\section{KAYNAKLAR}

1. Macchiarini P. Superior Vena Cava Obstruction. In: Patterson AG, Pearson G, Cooper JD, Deslauriers J, Rice TW, Luketich JD, Lerut AMR. 3rd ed Pearson's Thoracic and Esophageal Surgery, Churchill Livingstone Elsevier Philadelphia, 2008;p,1684-90.

2. Wan JF, Bezjak A. Superior vena cava syndrome. Hematol Oncol Clin N Am 2010;24:501-13.

3. Antonelli D, Turgeman Y, Kaveh Z, Artoul S, Rosenfeld T. Short-term thrombosis after transvenous permanent pacemaker insertion. Pacing Clin Electrophysiol 1989;12:280-2.

4. Lindsay HS, Chennells PM, Perrins EJ. Successful treatment by balloon venoplasty and stent insertion of obstruction of the superior vena cava by an endocardial pacemaker lead. Br Heart J 1994;71:363-5.

5. Stanford W, Doty DB. The role of venography and surgery in the management of patients with superior vena cava obstruction. Ann Thorac Surg 1986;41:158-63.

6. Ko GY, Byun JY, Choi BG, Cho SH. The vascular manifestations of Behçet disease: angiographic and CT findings. Br J Radiol 2000;73:1270-4.

7. Yu JB, Wilson LD, Detterbeck FC. Superior vena cava syndrome-a proposed classification system and algorithm for management. J Thorac Oncol 2008;3:811-4.

8. Dartevelle P, Levasseur P, Rojas-Miranda A, Le Brigand $\mathrm{H}$, Merlier M. Aspects chirurgicaux actuels des syndromes caves supérieurs. Rev Prat 1982;32:409-17.

9. Loeffler JS, Leopold KA, Recht A, Weinstein HJ, Tarbell NJ. Emergency prebiopsy radiation for mediastinal masses: impact on subsequent pathologic diagnosis and outcome. J Clin Oncol 1986;4:716-21.

10. Porte $H$, Metois D, Finzi L, et al. Superior vena cava syndrome of malignant origin. Which surgical procedure for which diagnosis? Eur J Cardiothorac Surg 2000;17:384-8.

11. Selcuk ZT, Firat P. The diagnostic yield of transbronchial needle aspiration in superior vena cava syndrome. Lung Cancer 2003;42:183-8.

12. Mineo TC, Ambrogi V, Nofroni I, et al. Mediastinoscopy in superior vena cava obstruction: analysis of 80 consecutive patients. Ann Thorac Surg 1999;68:223-6.

13. Wilson LD, Detterbeck FC, Yahalom J. Clinical practice. Superior vena cava syndrome with malignant causes. $\mathrm{N}$ Engl J Med 2007;356:1862-9.

14. Jahangiri $M$, Taggart DP, Goldstraw $P$. Role of mediastinoscopy in superior vena cava obstruction. Cancer 1993;71:3006-8.
15. Callejas MA, Rami R, Catalan M, et al. Mediastinoscopy as an emergency diagnostic procedure in superior vena cava syndrome. Scand J Thorac Cardiovasc Surg 1991;25:137-9.

16. Herth F, Becker HD, Ernst A. Conventional vs endobronchial ultrasound-guided transbronchial needle aspiration: a randomized trial. Chest 2004;125:322-5.

17. Rowell NP, Gleeson FV. Steroids, radiotherapy, chemotherapy and stents for superior vena caval obstruction in carcinoma of the bronchus. Cochrane Database Syst Rev 2001;CD001316.

18. Kaplan AP, Greaves MW. Angioedema. J Am Acad Dermatol 2005;53:373-92.

19. Ostler PJ, Clarke DP, Watkinson AF, et al. Superior vena cava obstruction:a modern management strategy. Clin Oncol (R Coll Radiol) 1997;9:83-9.

20. Rowell NP, Gleeson FV. Steroids, radiotherapy, chemotherapy and stents forsuperior vena caval obstruction in carcinoma of the bronchus: a systematic review. Clin Oncol (R Coll Radiol) 2002;14:338-51.

21. Schraufnagel DE, Hill R, Leech JA, Pare JA. Superior vena caval obstruction. Is it a medical emergency? Am J Med 1981;70:1169-74.

22. Adelstein DJ, Hines JD, Carter SG, et al. Thromboembolic events in patients with malignant superior vena cava syndrome and the role of anticoagulation. Cancer 1988;62:2258-62.

23. Perez-Soler R, McLaughlin P, Velasquez WS, et al. Clinical features and results of management of superior vena cava syndrome secondary to lymphoma. J Clin Oncol 1984;2:260-6.

24. Hennequin LM, Fade O, Fays JG, et al. Superior vena cava stent placement: results with the Wallstent endoprosthesis. Radiology 1995;196:353-61.

25. Irving JD, Dondelinger RF, Reidy JF, et al. Gianturco selfexpanding stents: clinical experience in the vena cava and large veins. Cardiovasc Intervent Radiol 1992;15:328-33.

26. Rosch J, Uchida BT, Hall LD, et al. Gianturco-Rosch expandable Z-stents in the treatment of superior vena cava syndrome. Cardiovasc Intervent Radiol 1992;15:319-27.

27. Bierdrager E, Lampmann LE, Lohle PN, et al. Endovascular stenting in neoplastic superior vena cava syndrome prior to chemotherapy or radiotherapy. Neth J Med 2005;63:20-3.

28. Greillier L, Barlesi F, Doddoli C, et al. Vascular stenting for palliation of superior vena cava obstruction in non-smallcell lung cancer patients: a future 'standard' procedure? Respiration 2004;71:178-83.

29. Kim YI, Kim KS, Ko YC, et al. Endovascular stenting as a first choice for the palliation of superior vena cava syndrome. J Korean Med Sci 2004;19:519-22.

30. Karla M, Gloviczki P, Andrews JC. Open surgical and endovascular treatment of superior vena cava syndrome caused by nonmalignant disease. J Vasc Surg 2003;38:215-23.

31. Dartevelle P, Macchiarini P, Chapelier A. Technique of superior vena cava resection and reconstruction. Chest Surg Clin N Am 1995;5:345-58.

32. Spaggiari L, Thomas $P$, Magdelenait P. Superior vena cava resection with prosthetic replacement for non-small 
cell lung cancer: Long-term results of a multicentric study. Eur J Cardiothorac Surg 2002;21:1080-6.

33. Alimi YS, Gloviczki P, Vrtiska TJ, et al. Reconstruction of the superior vena cava: Benefit of postoperative surveillance and secondary interventions. J Vasc Surg 1998;27:287.

34. Abner A. Approach to the patient who presents with superior vena cava obstruction. Chest 1993;103:394-7

35. Yildızeli B, Dartevelle PG, Fadel E, Mussot S, Chapelier A. Results of primary surgery with T4 non-small cell lung cancer during a 25-year period in a single center: the benefit is worth the risk. Ann Thorac Surg. 2008;86: 1065-75.

36. Henry M, Amor M, Henry I. The Hydrolyser thrombectomy catheter: A single-center experience. J Endovasc Surg 1998;5:24-31.

37. Bolad I, Karanam S, Mathew D, John R, Piemonte T, Martin D. Percutaneous treatment of superior vena cava obstruction following transvenous device implantation. Catheter Cardiovasc Interv 2005;65:54-9.

38. Warren WH, Piccione W, Faber LP. Superior vena caval reconstruction using autologous pericardium. Ann Thorac Surg 1998;66:291-2.

39. Doty DB. Bypass of superior vena cava: Six years experience with spiral vein graft for obstruction of superior vena cava due to benign and malignant disease. J Thorac Cardiovasc Surg 1982;83:326-38.

40. Dartevelle P, Macchiarini P, Chapelier A. Superior vena cava resection and reconstruction. In: Faber $\mathrm{P}$, ed. Techniques of Pulmonary Resection, Philadelphia: WB Saunders; 1995;345-58.

41. Gonzalez-Fajardo JA, Garcia-Yuste M, Florez S, Ramos G, Alvarez T, Coca JM. Hemodynamic and cerebral repercussions from surgical interruption of the superior vena cava. J Thorac Cardiovasc Surg 1994;107:1044-9.

42. Egelmeers A, Goor C, van Meerbeeck J, van den Weyngaert $D$, Scalliet $P$. Palliative effectiveness of radiation therapy in the treatment of superior vena cava syndrome. Bull Cancer Radiother 1996;83:153-7.

43. Suzuki K, Asamura H, Watanabe S, Tsuchiya. Combined resection of superior vena cava for lung carcinoma: Prognostic significance of patterns of superior vena cava invasion. Ann Thorac Surg 2004;78:1184-9.

44. Thomas P, Magnan PE, Moulin G, Giudicelli R, Fuentes P. Extended operation for lung cancer invading the superior vena cava. Eur J Cardiothorac Surg 1994;8:177-82.

45. Spaggiari L, Regnard JF, Magdeleinat P, Jauffret B, Puyo $P$, Levasseur $P$. Extended resections for bronchogenic carcinoma invading the superior vena cava system. Ann Thorac Surg 2000;69:233-6.

46. Spaggiari L, Thomas $P$, Magdeleinat $P$, et al. Superior vena cava resection with prosthetic replacement for nonsmall cell lung cancer: long-term results of a multicentric study. Eur J Cardiothorac Surg 2002;21:1080-6.

47. Spaggiari L, Magdeleinat $\mathrm{P}$, Kondo $\mathrm{H}$, et al. Results of superior vena cava resection for lung cancer. Analysis of prognostic factors. Lung Cancer 2004;44:339-46.

48. Picquet J, Blin V, Dussaussoy C, Jousset Y, Papon X, Enon B. Surgical reconstruction of the superior vena cava system: indications and results. Surgery. 2009;145:93-9.

49. Lanuti M, De Delva PE, Gaissert HA, et al. Review of superior vena cava resection in the management of benign disease and pulmonary or mediastinal malignancies. Ann Thorac Surg. 2009;88:392-7. 